Trauma Surgery \& Acute Care Open

\title{
Emergency carotid artery stenting for progressive traumatic internal carotid artery occlusion
}

\author{
Yuta Oyama 이, ${ }^{1}$ Takeshi Uno, ${ }^{1}$ Masahiro Asami, ${ }^{1}$ Takahiro Onuki, ${ }^{2}$ Masahiro Shin ${ }^{1}$
}

${ }^{1}$ Neurosurgery, Teikyo University School of Medicine, Tokyo, Japan

2Emergency Medicine, Teikyo University School of Medicine, Tokyo, Japan

Correspondence to DrYuta Oyama; yutang0122@ gmail.com (c) Author(s) (or their employer(s)) 2022. Re-use permitted under CC BY-NC. No commercial re-use. See rights and permissions. Published by BMJ.

To cite: Oyama $Y$, Uno $T$,

Asami M, et al. Trauma Surg

Acute Care Open

2022:7:e000873.

\section{CASE PRESENTATION}

A woman in her early 40s experienced an accidental fall down stairs requiring transfer to our hospital. When she arrived at our emergency department, her consciousness was clear, and assessment of vital signs revealed: heart rate, 62 beats/min; blood pressure, 174/119 $\mathrm{mm} \mathrm{Hg}$; respiration rate, 16 breaths/ min; and saturation of percutaneous oxygen level, 100\%. Neurological examination revealed motor paresis of the right upper and both lower limbs with sensory disturbances below the level of the 4th thoracic dermatome. Cervical CT showed dislocation between the 6 th and 7 th cervical vertebrae. Simultaneously, CT angiography showed stenosis of the right internal carotid artery (ICA), but cerebral blood flow remained normal (figure 1). The patient showed cervical cord injury classified as American Spinal Injury Association Impairment scale A and underwent emergency surgical vertebroplasty. However, postoperatively, she presented with mild paresis of the left upper limb. MRI of the head was performed on postoperative day (POD) 1, disclosing cerebral ischemia of the right centrum semiovale and markedly reduced flow in the ipsilateral ICA. We started continuous administration of intravenous heparin, but left-sided hemiparesis remained unimproved. On POD2, second MRI disclosed further enlargement of the ischemic areas and defective flow signal in the right ICA (figure 2). This led us to perform cerebral angiography, showing near occlusion of the right ICA and no cross-flow from the left ICA. These findings suggested a state of progressive ischemia in the right cerebral hemisphere.

\section{WHAT WOULD YOU DO NEXT?}

A. Carotid endarterectomy on the right side

B. Extracranial-intracranial (EC-IC) bypass surgery on the right side

C. Placement of a carotid artery stent in the right ICA

D. Endovascular angioplasty of the right ICA

\section{WHAT WE DID AND WHY?}

Angiography of the right ICA showed a severely stenotic but intact lumen of the artery, and we decided to perform endovascular carotid artery stenting. Before the procedure, the patient orally took $200 \mathrm{mg}$ of aspirin and $300 \mathrm{mg}$ of clopidogrel, and $80 \mathrm{mg}$ of sodium ozagrel was administered intravenously. A 5-Fr sheathless guiding catheter (ASAHI FUBUKI; Asahi Intecc Co., Aichi, Japan) was introduced into the common carotid artery. Carefully following the arterial lumen of the right ICA, hydrophilic guidewires (CHIKAI 14; Asahi
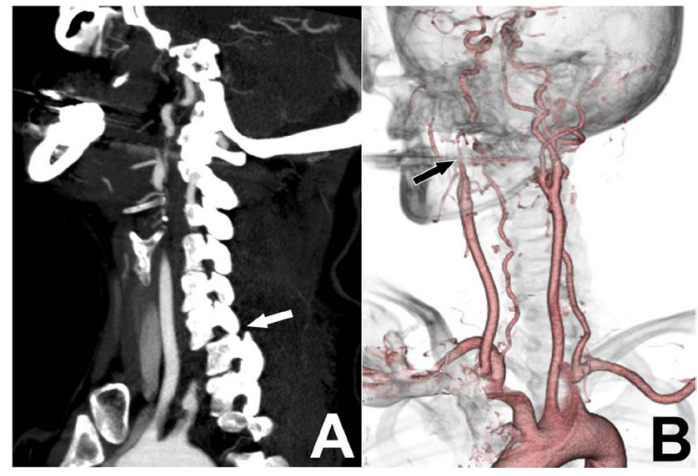

Figure 1 Head and neck CT with contrast enhancement on arrival at the emergency department. (A) CT on sagittal section discloses cervical dislocation between the 6th and 7th cervical vertebrae (white arrow). (B) CT angiography shows stenosis of the right internal carotid artery (ICA) (black arrow) and a patent left ICA.

Intecc Co.) were slowly advanced to the distal part of the stenotic ICA, where a carotid artery stent ( $8 \mathrm{~mm}$ in diameter, $29 \mathrm{~mm}$ in length, Carotid Wallstent; Boston Scientific, Natick, MA) was deployed. After the procedure, angiography of the common carotid artery revealed recovery of anterograde blood flow in the right ICA (figure 3). After this procedure, symptoms stabilized and the patient was transferred to another hospital for rehabilitation of remaining motor deficits.

\section{DISCUSSION}

We have presented the case of a patient who underwent carotid artery stenting for ICA injury associated with traumatic cervical fracture due to trauma. In this case, we initially selected conservative management because CT angiography disclosed

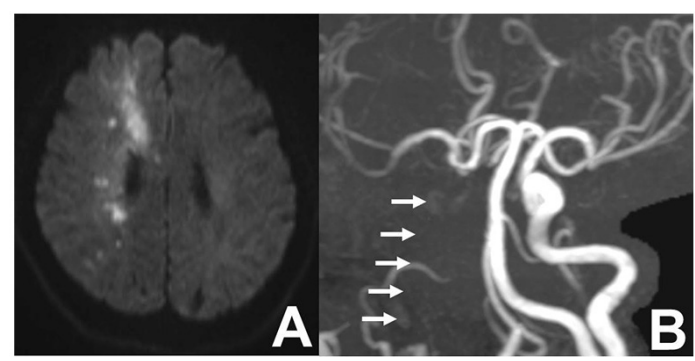

Figure 2 MRI on postoperative day 2. (A) Diffusionweighted MRI discloses enlargement of ischemic areas in the right centrum semiovale. (B) MR angiography shows a defect in the flow signal of the right internal carotid artery (white arrows) with preservation of the right middle cerebral artery. 


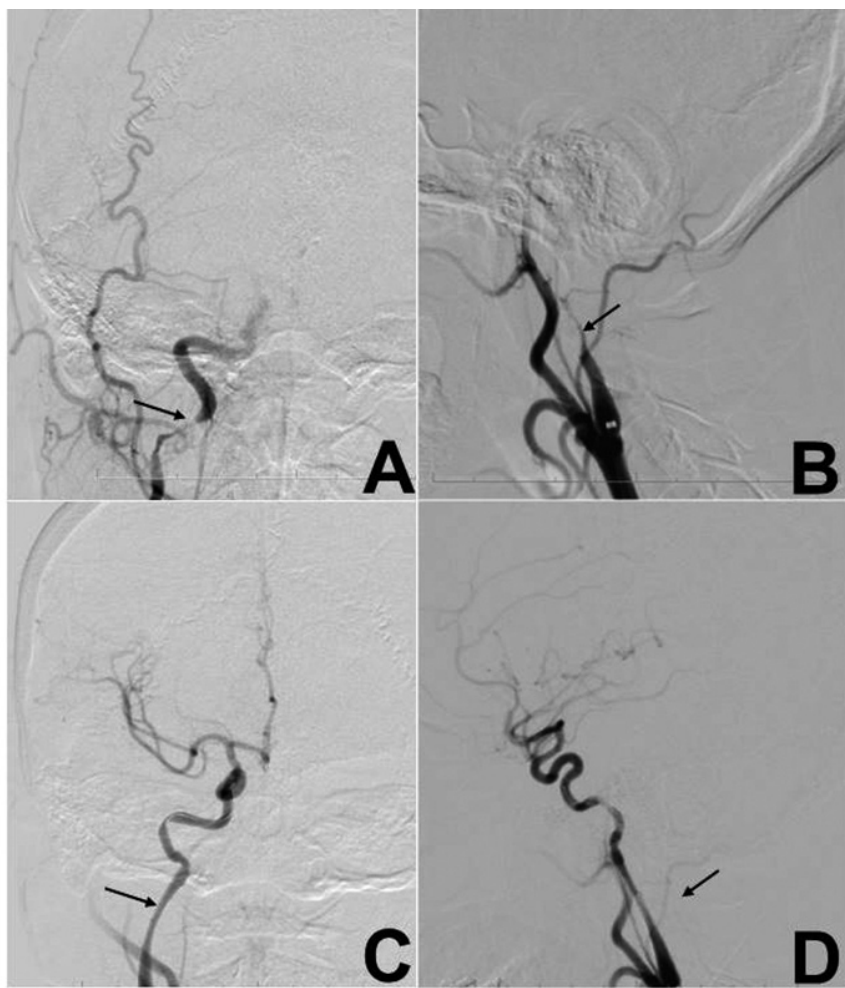

Figure 3 Cerebral angiography before and after endovascular carotid artery stenting. $(A, B)$ Anteroposterior view $(A)$ and lateral view $(B)$ show near occlusion of the right internal carotid artery (ICA) (black arrows). (C, D) Anteroposterior view (C) and lateral view (D) show recovery of antegrade blood flow with cerebral circulation in the right hemisphere after endovascular carotid artery stenting in the stenotic area of the right ICA.

sufficient cerebral blood flow. However, the situation changed after cervical vertebroplasty. She developed additional neurological symptoms and we finally performed endovascular carotid stent placement to stop further progression of symptoms caused by cerebral ischemia on POD2.

Blunt cerebrovascular artery injury (BCVI) can be generally divided into two categories: carotid artery injury (CAI) and vertebral artery injury (VAI). BCVI is very rare, accounting for less than $1 \%$ of all blunt traumas, with car accidents as the most common cause, followed by falls. CAI reportedly shows higher mortality rates than VAI, with significant factors including reduced level of consciousness with Glasgow Coma Scale less than 6, presence of pyramidal bone fracture, diffuse axonal injury, and facial bone fracture (Le Fort type II/III). In addition, CAI of the craniocervical junction is often associated with skull base fractures and carries a high risk of being life-threatening. To determine the therapeutic options for BCVI, the Denver grading scale is often applied. In our case, MRI performed after surgical vertebroplasty showed severe ICA stenosis classified as grade II ( $\geq 25 \%$ luminal stenosis). However, after conservative treatment, stenosis advanced to grade IV (vessel occlusion) with further progression of symptoms, indicating a need for certain interventions. Learning from this case, although CT angiography is highly sensitive for diagnosing BCVI, timely radiographic examination with MRI is crucial. MRI is less invasive, easier to repeat within short periods, and enables the evaluation of cerebral ischemia, which is essential to decide the indications for additional cerebral angiography and, eventually, the timing of interventions with endovascular carotid artery revascularization.

Contributors All individuals who met the authorship criteria are listed as authors, and all authors attest that they participated in the study to take public responsibility for its content. All authors certify that they have participated in the study sufficiently to take public responsibility for its content, including participation in the conception, writing, and revision of the paper.

Funding The authors have not declared a specific grant for this research from any funding agency in the public, commercial or not-for-profit sectors.

Competing interests None declared.

Patient consent for publication Not applicable.

Ethics approval In this case, a specific approval of IRB committee is not necessary because the patient provided written informed consent to use the data related to the examination results (such as numerical values, pictorial data, and tissue preparations) for the education of clinical trainees and academic presentations. Also, the patient consent has been comprehensively obtained in the form of an opt-out style. Participants gave informed consent to participate in the study before taking part.

Provenance and peer review Not commissioned; internally peer reviewed.

Open access This is an open access article distributed in accordance with the Creative Commons Attribution Non Commercial (CC BY-NC 4.0) license, which permits others to distribute, remix, adapt, build upon this work non-commercially, and license their derivative works on different terms, provided the original work is properly cited, appropriate credit is given, any changes made indicated, and the use is non-commercial. See: http://creativecommons.org/licenses/by-nc/4.0/.

\section{ORCID iD}

Yuta Oyama http://orcid.org/0000-0001-6274-1216 